\title{
GCU
}

Glasgow Caledonian

University

University for the Common Good

\section{Haemodynamic responses to radial motion in the visual cortex}

Wijeakumar, Sobanawartiny; Shahani, Uma; Simpson, William A.; McCulloch, Daphne

\section{Published in:}

Journal of Near Infrared Spectroscopy

DOI:

10.1255/jnirs. 1056

Publication date:

2013

Document Version

Publisher's PDF, also known as Version of record

Link to publication in ResearchOnline

Citation for published version (Harvard):

Wijeakumar, S, Shahani, U, Simpson, WA \& McCulloch, D 2013, 'Haemodynamic responses to radial motion in the visual cortex', Journal of Near Infrared Spectroscopy, vol. 21, no. 4, pp. 231-236.

https://doi.org/10.1255/jnirs.1056

\section{General rights}

Copyright and moral rights for the publications made accessible in the public portal are retained by the authors and/or other copyright owners and it is a condition of accessing publications that users recognise and abide by the legal requirements associated with these rights.

Take down policy

If you believe that this document breaches copyright please view our takedown policy at https://edshare.gcu.ac.uk/id/eprint/5179 for details of how to contact us. 


\title{
Haemodynamic responses to radial motion in the visual cortex
}

\author{
Sobanawartiny Wijeakumar, ${ }^{\mathrm{a}, \mathrm{b}}$ Uma Shahani, ${ }^{a}$ William A. Simpson ${ }^{c}$ and Daphne L. McCulloch ${ }^{\mathrm{a}, \mathrm{d}}$ \\ aGlasgow Caledonian University, Vision Sciences, Department of Life Sciences, G4 OBA Glasgow, UK. \\ E-mail: sobanawartiny-wijeakumar@uiowa.edu \\ bUniversity of lowa, Department of Psychology, lowa City, IA 52245, USA \\ 'School of Psychology, University of Plymouth, Drake Circus, PL4 8AA Plymouth, UK \\ ¿University of Waterloo, Optometry and Vision Science, 200 University Avenue West, Waterloo, ON N2L 3G1, Canada
}

\begin{abstract}
Functional near-infrared spectroscopy (fNIRS) is an optical imaging technique that relies on emitting near-infrared light into cortical tissue to measure changes in haemoglobin concentrations as a result of stimulation. The purpose of this study was to observe haemodynamic changes in response to moving stimuli over the primary visual cortex. The test stimuli were radially expanding and contracting concentric gratings and the control stimulus was a matched stationary pattern. A two-channel oximeter (0xiplex TS) was used to record changes in oxyhaemoglobin $(\mathrm{HbO})$, de-oxyhaemoglobin $(\mathrm{Hb})$ and total haemoglobin concentrations (THb). An increase in haemodynamic activation was observed $20 \mathrm{~s}$ after the onset of motion and maintained for up to $20 \mathrm{~s}$ following motion offset $130 \mathrm{~s}$ time window). This was compared to a time window of $10 \mathrm{~s}$ before the offset of the stationary presentation. Differences between expanding and contracting motion did not achieve significance at any of the locations. However, a significantly larger HbO response was observed across the $30 \mathrm{~s}$ time window when compared to the baseline window at both occipital locations. Preliminary results from more temporal locations also showed a similar trend. It is suggested that the delayed rise in $\mathrm{HbO}$ levels could be due to an inconsistent maintenance of luminance and contrast-related features of the moving stimuli in V1 receptive fields. Furthermore, motion-after effects could have contributed to delaying the drop to baseline levels. The current study has shown some evidence that fNIRS can be used to record haemodynamic responses to moving stimuli from the visual cortex. We suggest that longer durations of randomised moving, stationary and grey screen presentations would be useful in teasing apart pure motion responses and after-effects. fNIRS could also potentially be used to investigate haemodynamic changes in disorders such as amblyopia that present with motion processing deficits.
\end{abstract}

Keywords: fNIRS, motion, visual cortex, imaging

\section{Introduction}

Functional near infrared spectroscopy (fNIRS) is an optical imaging technique that relies on the principle of shining light of different wavelengths (visible and near infrared) into tissue to estimate absolute and relative changes in haemoglobin concentration as a response to stimulation. Specifically, studies on visual perception have shown increased activation over areas of the visual cortex as a result of exposure to a variety of visual stimuli such as flashes, ${ }^{1}$ checkerboards ${ }^{2-8}$ and faces 9,10 However, one important class of visual stimuli which has not been studied adequately using fNIRS, is that of visual motion. Other studies investigating temporal and spatial correlates of visual motion have used visual evoked potentials (VEPs) ${ }^{11-14}$ and functional magnetic resonance imaging (fMRI), ${ }^{15-19}$ respectively. fNIRS is unique in that it provides spatio-temporal resolution, is inexpensive, simple and practical to use on people of any age group and it can 
also directly measure absolute changes in haemoglobin concentrations. If fNIRS were to be sensitive enough to detect changes in haemoglobin concentration in response to visual motion, it could potentially be used to investigate disorders such as amblyopia that present with motion-processing deficits. Therefore, in the current study, our aim was to compare changes in chromophore concentrations between moving concentric gratings and corresponding stationary presentations in normal observers.

\section{Materials and methods}

\section{Observers}

Nine observers were recruited from university students and employees lage range: 20-35y). All observers had visual acuity of $6 / 6$ or better in each eye (Bailie-Lovie LogMAR chart) with appropriate refractive correction if required. Also, they had no history of any visual disorders. In accordance with the declaration of Helsinki, all participants gave their informed consent and the study had the approval of the local ethical committee.

\section{Visual stimulation}

Stimuli were presented on a 17 inch monitor (liyama, Hoofddorp, The Netherlands) refreshed at $100 \mathrm{~Hz}$. Observers were asked to fixate on a stationary marker at the centre of the screen at a test distance of 1 metre (field size of $20.7^{\circ} \times 15.4$ ). A grey screen was presented at the start for $30 \mathrm{~s}$, to provide a pre-trial baseline. Test stimuli were sinusoidally modulated radially expanding and contracting concentric rings with a spatial frequency of 0.333 cycles per degree and $90 \%$ contrast plotted at a resolution of $800 \times 600$. The test stimuli were alternated with stationary presentations of the same for $30 \mathrm{~s}$ each (Figure 1). Each observer was presented with stimuli in a six minute session which consisted of six 1 min long segments (30 s of expansion/ contraction followed by $30 \mathrm{~s}$ of stationary presentation).

\section{fNIRS recordings}

A fNIRS oximeter (OxiplexTS ISS Inc., Champaign, Illinois, USAl was used to measure absolute changes in haemoglobin concentrations. Eight sources were modulated at $110 \mathrm{MHz}$ and emitted light at $834 \mathrm{~nm}$ (four sources) and $692 \mathrm{~nm}$ (four sources). The sensor was a flat flexible pad that housed a detector and four emitter pairs at fixed distances from each other $(1.93-3.51 \mathrm{~cm})$. Detected light was used to calculate the slopes of averaged light intensity [direct current $(D C)$ ], modulated intensity [alternating current $(A C)$ ] and the $\phi$ (phase) from the fixed emitter-detector measurements. These values were converted to absolute concentrations of oxyhaemoglobin $(\mathrm{HbO})$ and deoxy haemoglobin $(\mathrm{Hb})$ using a modified version of the Beer-Lambert Law. ${ }^{2}$ Total haemoglobin concentration ( $\mathrm{THb}$ ) was calculated to be the sum of $\mathrm{HbO}$ and $\mathrm{Hb}$. Recordings were taken from nine observers over locations 01 and 02 (based on the International 10-20 system of Electrode Placement). ${ }^{20}$ Locations overlying the

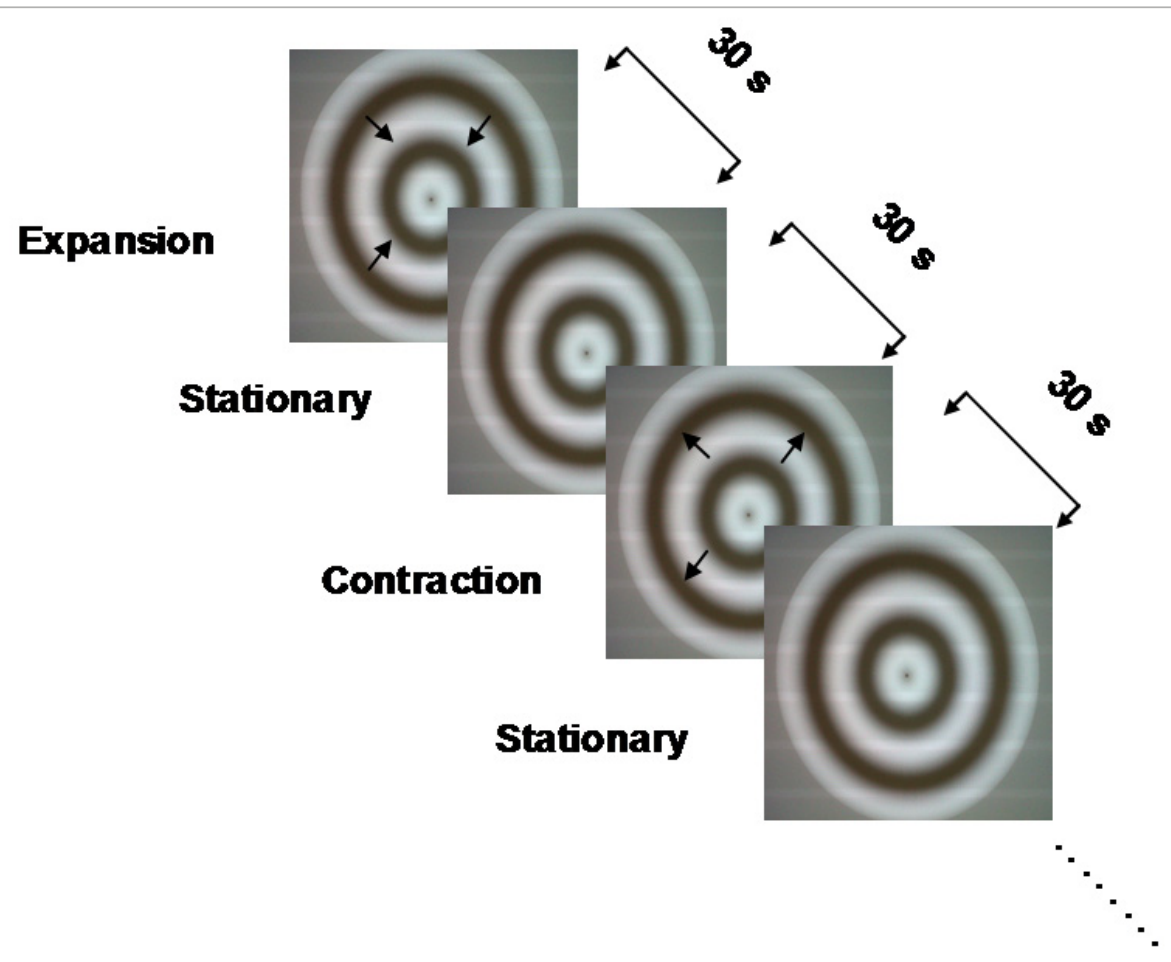

Figure 1. Stimuli were radially moving expanding and contracting concentric circles alternated with stationary presentations. 


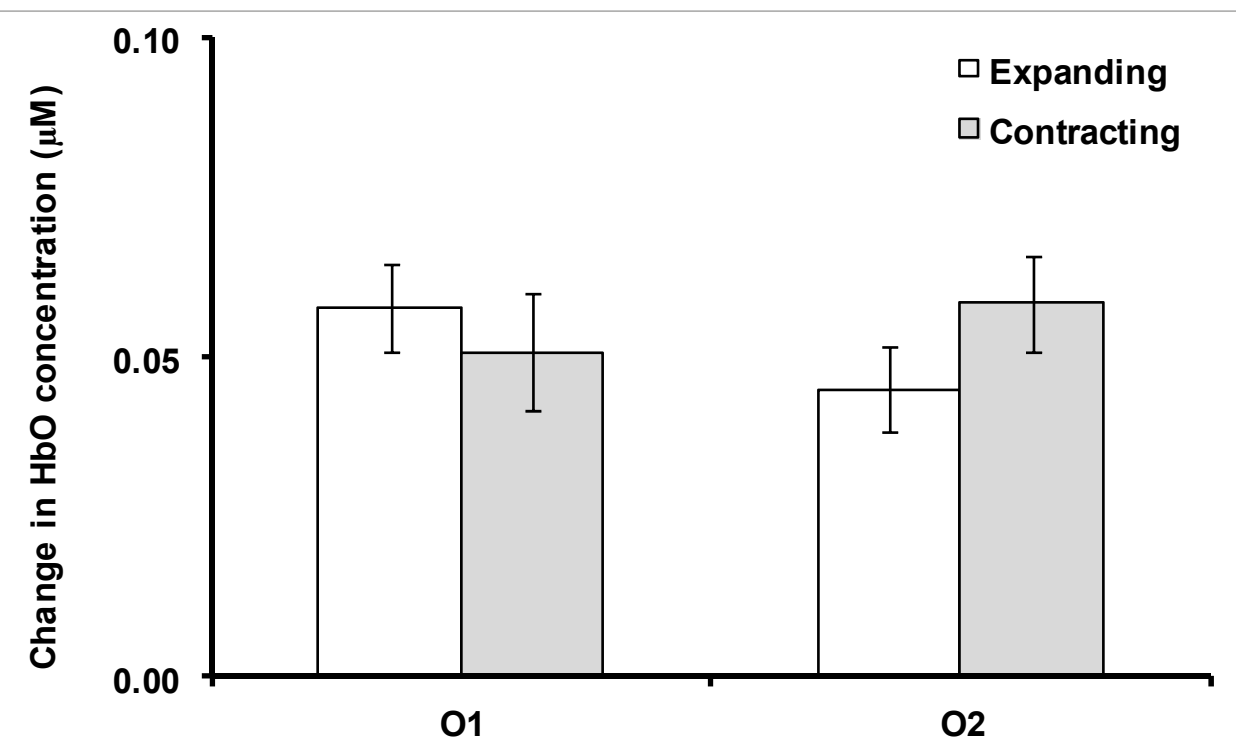

\section{Location}

Figure 2. Averaged $\mathrm{HbO} \pm$ standard error of mean: responses during onset response time window to expanding and contracting radial motion at locations $\mathrm{O}_{1}$ and $\mathrm{O}_{2}$.

central sulcus along the midline were ignored as they have previously been shown to produce non-significant haemodynamic responses to visual stimuli. ${ }^{8}$ In five of these observers, we also recorded from scalp locations overlying the $\mathrm{P}_{7}-\mathrm{PO}_{7}$ and $\mathrm{P}_{8}-\mathrm{PO}_{8}$ regions.

\section{Data Analysis}

Each six minute segment was normalised with respect to the pre-stimulus grey screen baseline. The data were de-trended and each one minute segment $130 \mathrm{~s}$ of expansion/contraction and 30 s of stationaryl was normalised with respect to the last $10 \mathrm{~s}$ of its corresponding stationary presentation. The response reached baseline levels consistently across all observers during this time window of $10 \mathrm{~s}$. Twenty seconds after motion stimulus onset, $\mathrm{HbO}$ levels rose and stayed above baseline levels during the time window between $20 \mathrm{~s}$ after motion stimulus onset and $20 \mathrm{~s}$ after stationary stimulus onset. Therefore, two windows were selected and haemoglobin concentration levels were averaged for the statistical analyses-onset response (duration $30 \mathrm{~s}$ ) and baseline (duration $10 \mathrm{~s}$ ). IBM Statistical Package for the Social Sciences (SPSS Version 16.0; www-01.ibm.com/software/ analytics/spss// was used to carry out statistical analyses. First, comparisons between $\mathrm{HbO}$ responses to expanding and contracting stimuli were made at both locations for the onset response window [two factor repeated measure of analysis of variance (ANOVA)]. Observing no differences, responses across both stimuli were pooled together and compared at each of the two time windows (baseline and onset responsel in two-factor repeated measures of ANOVA. Greenhouse-Geisser correction epsilon was used in cases where the Mauchly's sphericity test for normality was violated to correct the degrees of freedom.

\section{Results}

Changes in $\mathrm{HbO}, \mathrm{Hb}$ and $\mathrm{THb}$ concentration levels were observed in response to the moving visual stimuli at both occipital locations. No significant differences were observed between expanding and contracting radial motion at both locations (Figure 2). Data were pooled across expanding and contracting motion (Figure 3). HbO levels slowly increased following a lag of nearly 20-25s. This response lasted for up to $20 \mathrm{~s}$ into the stationary presentation period. Following this, the response dropped to baseline levels. A relative increase in $\mathrm{THb}$ and a decrease in $\mathrm{Hb}$ concentrations were also observed. Statistical comparisons revealed that $\mathrm{HbO}$ levels during the onset response was significantly larger than the baseline levels at both locations $[F(1,8)=40 ; p<0.001]$. Differences between locations did not achieve significance.

Preliminary recordings made from the scalp locations overlying P7-P07 and P8-P08 on five observers also showed the same trend as that of $\mathrm{O} 1$ and $\mathrm{O} 2$ (Figure 4).

\section{Discussion}

fNIRS is an accessible technique for measuring absolute changes in chromophore concentration in response to cortical stimulation and can be employed in normative studies of adults, infants and children and also across 


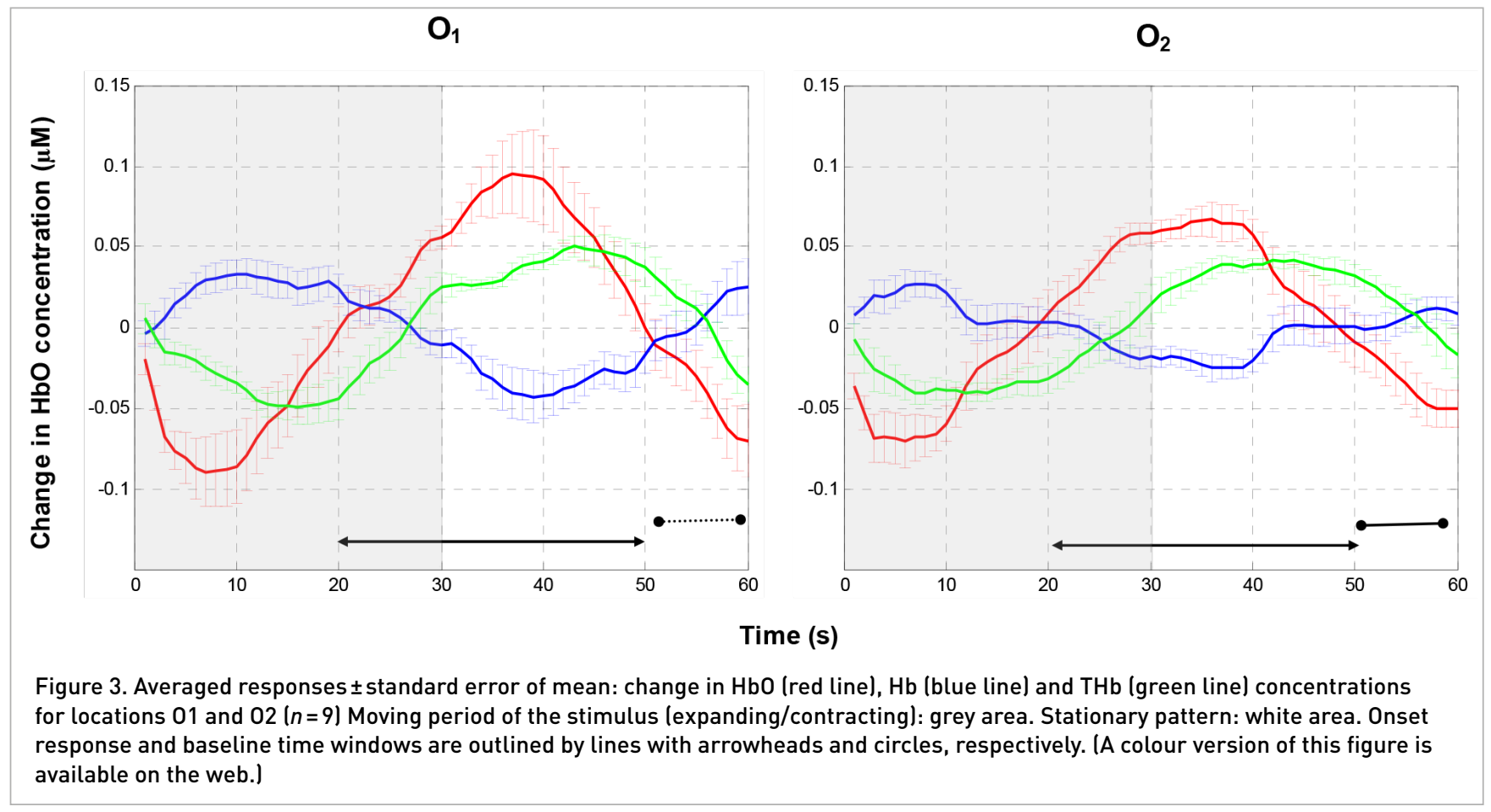

atypical populations. Specifically, some studies have investigated haemodynamic responses to visual stimuli using fNIRS 1,2,4-6,21-23 and very few have explored changes in chromophore concentration to complex properties such as motion $^{7,24}$ and depth. ${ }^{8}$ Previously, Schroeter and colleagues (24) used rotating L-shaped structures and a reversing checkerboard to compare responses obtained from regions within the visual cortex. ${ }^{7}$ In another study by Hashimoto and colleagues, haemodynamic responses to peripheral drift illusion were observed at locations overlying middle temporal (MT). ${ }^{24}$ Whilst both studies have detected changes in haemoglobin levels, standard motion stimuli and responses to real motion and pattern could not be clearly teased apart. In the current study, we have used conventional motion stimuli
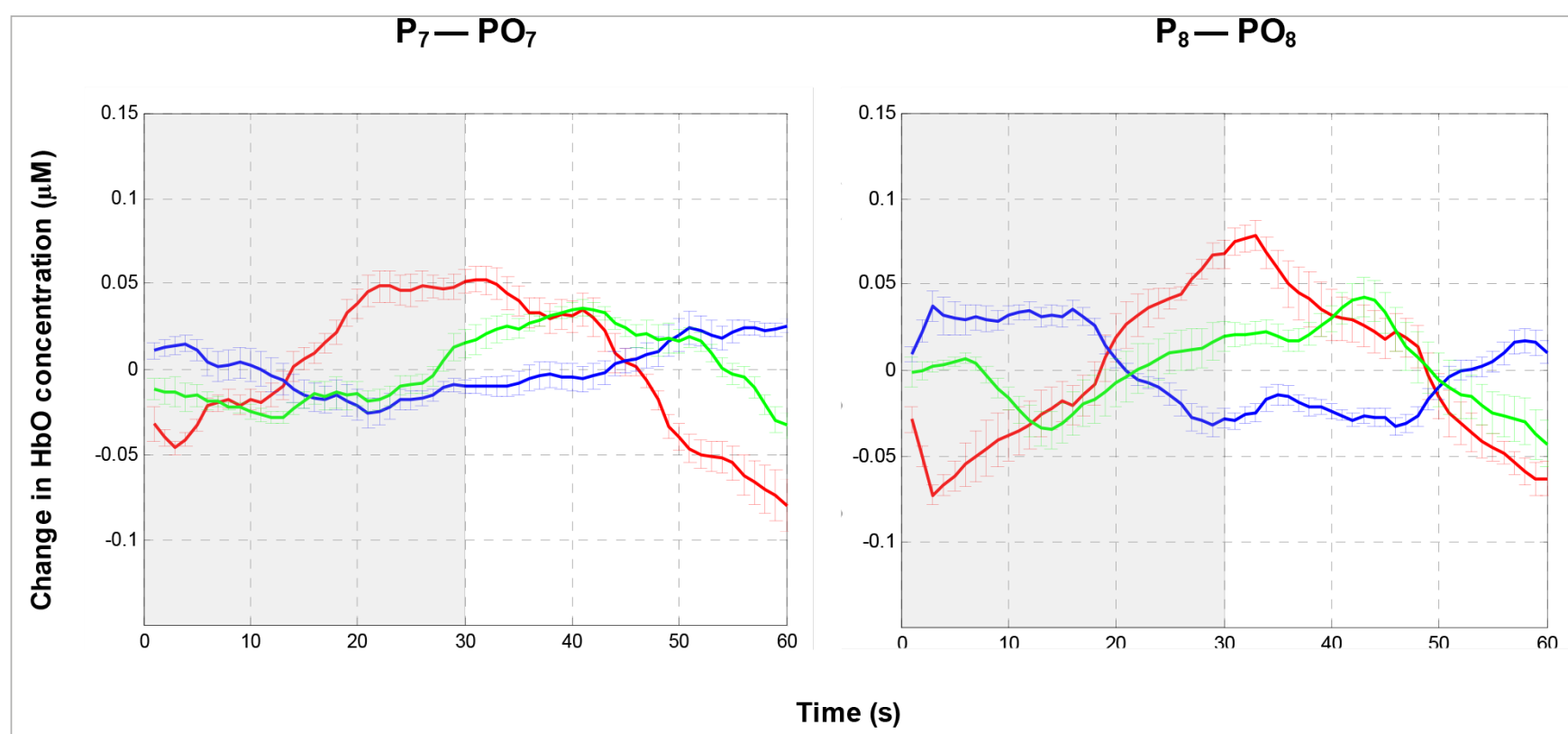

Figure 4. Averaged responses \pm standard error of mean: change in $\mathrm{HbO}$ (red line), $\mathrm{Hb}$ (blue line) and THb (green line) concentrations for locations P7-P07 and P8-P08 ( $n=5)$. Moving period of the stimulus (expanding/contracting): grey area. Stationary pattern: white area. 
such as radially expanding and contracting concentric grat-

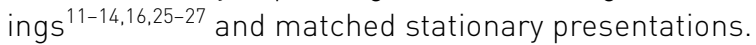

In accordance with results from Bach and colleagues (2000), no significant differences were observed between responses to expanding and contracting moving presentations. ${ }^{12}$ However, these results are in disagreement with other studies that have reported one type of motion to be stronger than the other. ${ }^{14,26,28-31}$

Studies from our lab have shown that $\mathrm{HbO}$ levels, in response to visual stimulation such as checkerboards and stereograms, start to rise within $10 \mathrm{~s}$ of stimulus onset. ${ }^{2,8,23}$ However, in the current study, a longer delay was observed (20s following moving stimulus onset). We suggest that luminance and contrast-related features of moving presentations, unlike stationary presentations, were not maintained for long enough on $\mathrm{V} 1$ receptive cells to elicit an early and stable rise in $\mathrm{HbO}$ levels. An additive influence of these inconsistent effects could have eventually resulted in a delayed rise in the response. Alternatively, motion after-effects could also have accounted for the late recovery to baseline levels. Whilst delays analogous to that of the current study have not been reported in fMRI literature, Tootell and colleagues ${ }^{15}$ have shown that expanding and contracting motion produced strong after-effects that leaked into successive presentations. ${ }^{19}$ In the current study, these effects were observed at more temporal locations, thought to be specifically motion-sensitive (likely overlying area MT).

Whilst these are only preliminary results, the current study has shown that fNIRS is sensitive enough to detect motionspecific responses. We believe that these effects can be further enhanced in a paradigm with a randomised order of moving, stationary and grey screen presentations of longer durations. This would not only give the signals enough time to rise from and drop to baseline, but also extract specific responses to after-effects. If this could be successfully demonstrated in normal observers across parts of the visual cortex, one could potentially use fNIRS to investigate haemodynamic correlates of visual disorders such as amblyopia that present with motion-processing problems.

\section{Acknowledgement}

Sobanawartiny Wijeakumar was supported by a grant from Fight for Sight, UK

\section{References}

1. A. Villringer, J. Planck, C. Hock, L. Schleinkofer and U. Dirnagl, “Near infrared spectroscopy (NIRS): a new tool to study hemodynamic changes during activation of brain function in human adults", Neurosci. Lett. 154(1-2), 101 (1993). doi: 10.1016/0304-3940(93)90181-J

2. M.A. Mclntosh, U. Shahani, R.G. Boulton and D.L. McCulloch, "Absolute quantification of oxygenated hemoglobin within the visual cortex with functional near infrared spectroscopy (fNIRS)", Invest. Ophthalmol. Vis. Sci. 51(9), 4856 (2010). doi: $10.1167 /$ iovs.09-4940

3. H. Radhakrishnan, W. Vanduffel, H.P. Deng, L. Ekstrom, D.A. Boas and M.A. Franceschini, "Fast optical signal not detected in awake behaving monkeys", Neuroimage 45(2), 410 (2009). doi: 10.1016/j.neuroimage.2008.12.014

4. T. Näsi, K. Kotilahti, T. Noponen, I. Nissilä, L. Lipiäinen and P. Meriläinen, "Correlation of visual-evoked hemodynamic responses and potentials in human brain", Exp. Brain Res. 202(3), 561 (2010). doi: 10.1007/s00221-0102159-9

5. H. Obrig, H. Israel, M. Kohl-Bareis, K. Uludag, R. Wenzel, B. Müller, G. Arnold and A. Villringer, "Habituation of the visually evoked potential and its vascular response: implications for neurovascular coupling in the healthy adult", Neurolmage 17(1), 1 (2002). doi: $10.1006 /$ nimg.2002.1177

6. K. Takahashi, S. Ogata, Y. Atsumi, R. Yamamoto, S. Shiotsuka, A. Maki, Y. Yamashita, T. Yamamoto, H. Koizumi, H. Hirasawa and M. Igawa, "Activation of the visual cortex imaged by 24-channel near-infrared spectroscopy", J. Biomed. Opt. 5(1), 93 (2000). doi: $\underline{10.1117 / 1.429973}$

7. M.L. Schroeter, M.M. Bücheler, K. Müller, K. Uludag, H. Obrig, G. Lohmann, M. Tittgemeyer, A. Villringer and D.Y. von Cramon, "Towards a standard analysis for functional near-infrared imaging", Neuroimage 21(1), 283 (2004). doi: 10.1016/i.neuroimage.2003.09.054

8. S. Wijeakumar, U. Shahani, D.L. McCulloch and W.A. Simpson, "Neural and vascular responses to fused binocular stimuli: A VEP and fNIRS study", Invest. Ophthalmol. Vis. Sci. 53(9), 5881 (2012). doi: $10.1167 /$ iovs.12-10399

9. J. Carlsson, H. Lagercrantz, L. Olson, G. Printz and M. Bartocci, "Activation of the right fronto-temporal cortex during maternal facial recognition in young infants", Acta Paediatr. 97(9), 1221 (2008). doi: 10.1111/i.16512227.2008.00886.x

10. Y. Otsuka, E. Nakato, S. Kanazawa, M.K. Yamaguchi, S. Watanabe and R. Kakigi, "Neural activation to upright and inverted faces in infants measured by near infrared spectroscopy", Neuroimage 34(1), 399 (2007). doi: 10.1016/j.neuroimage.2006.08.013

11. M. Bach and D. Ullrich, "Contrast dependency of motion-onset and pattern-reversal VEPs: interaction of stimulus type, recording site and response component", Vision Res. 37(13), 1845 (1997). doi: 10.1016/S00426989(96)00317-3

12. M. Bach and M.B. Hoffmann, "Visual motion detection in man is governed by non-retinal mechanisms", Vision Res. 40(18), 2379 (2000). doi: 10.1016/S0042-6989(00)00106-1

13. M. Kuba, Z. Kubová, J. Kremlácek and J. Langrová, "Motion-onset VEPs: characteristics, methods, and diagnostic use", Vision Res. 47(2), 189 (2007). doi: 10.1016/j. visres.2006.09.020 
14. C. Delon-Martin, R. Gobbelé, H. Buchner, B.A. Haug, A. Antal, F. Darvas and W. Paulus, "Temporal pattern of source activities evoked by different types of motion onset stimuli", Neurolmage 31(4), 1567 (2006). doi: 10.1016/i.neuroimage.2006.02.013

15. R.B. Tootell, J.B. Reppas, A.M. Dale, R.B. Look, M.I. Sereno, R. Malach, T.J. Brady and B.R. Rosen, "Visual motion aftereffect in human cortical area MT revealed by functional magnetic resonance imaging", Nature 375(6527), 139 (1995). doi: 10.1038/375139a0

16. S.O. Murray, B.A. Olshausen and D.L. Woods, "Processing shape, motion and three-dimensional shape-from-motion in the human cortex", Cereb. Cortex 13(5), 508 (2003). doi: 10.1093/cercor/13.5.508

17. S. Nishida, Y. Sasaki, I. Murakami, T. Watanabe and R.B. Tootell, "Neuroimaging of direction-selective mechanisms for second-order motion", J. Neurophysiol. 90(5), 3242 (2003). doi: 10.1152/jn.00693.2003

18. R.B. Tootell, J.D. Mendola, N.K. Hadjikhani, P. J. Ledden, A.K. Liu, J.B. Reppas, M.I. Sereno and A.M. Dale, "Functional analysis of V3A and related areas in human visual cortex", J. Neurosci. 17(18), 7060 (1997)

19. R.B. Tootell, J.B. Reppas, K.K. Kwong, R. Malach, R.T. Born, T.J. Brady, B.R. Rosen and J.W. Belliveau, "Functional analysis of human MT and related visual cortical areas using magnetic resonance imaging", J. Neurosci. 15(4), 3215 (1995).

20. G.H. Klem, H.O. Luders, H.H. Jasper and C. Elger, "The ten-twenty electrode system of the International Federation. The International Federation of Clinical Neurophysiology". Electroencephalogr. Clin. Neurophysiol. Suppl. 52, 3 (1999).

21. M.M. Plichta, S. Heinzel, A.C. Ehlis, P. Pauli and A.J. Fallgatter, "Model-based analysis of rapid event-related functional near-infrared spectroscopy (NIRS) data: a parametric validation study", Neurolmage 35(2), 625 (2007). doi: 10.1016/j.neuroimage.2006.11.028

22. J.H. Meek, C.E. Elwell, M.J. Khan, J. Romaya, J.S. Wyatt, D.T. Delpy and S. Zeki, "Regional changes in cerebral haemodynamics as a result of a visual stimulus measured by near infrared spectroscopy", Proc. Biol. Sci.

261(1362), 351 (1995). doi: 10.1098/rspb.1995.0158

23. S. Wijeakumar, U. Shahani, W.A. Simpson and D.L. McCulloch, "Localization of hemodynamic responses to simple visual stimulation: an fNIRS study", Invest. Ophthalmol. Vis. Sci. 53(4), 2266 (2012). doi: $\underline{10.1167 /}$ iovs.11-8680

24. T. Hashimoto, Y. Minagawa-Kawai and S. Kojima, "Motion illusion activates the visual motion area of the brain: a near-infrared spectroscopy (NIRS) study", Brain Res. 1077(1), 116 (2006). doi: 10.1016/j.brainres.2005.11.050

25. C.Y. Yang, J.C. Hsieh and Y. Chang, "An MEG study into the visual perception of apparent motion in depth", Neurosci. Lett. 403(1-2), 40 (2006). doi: 10.1016/j.neulet.2006.04.046

26. B.J. Geesaman and N. Qian, "A novel speed illusion involving expansion and rotation patterns", Vision Res. 36(20), 3281 (1996). doi: 10.1016/0042-6989(96)00054-5

27. M.C. Morrone, M. Tosetti, D. Montanaro, A. Fiorentini, G. Cioni and D.C. Burr, "A cortical area that responds specifically to optic flow, revealed by fMRI", Nat. Neurosci. 3(12), 1322 (2000). doi: $\underline{\text { 10.1038/81860 }}$

28. F. Bremmer, J.R. Duhamel, S. Ben Hamed and W. Graf, "Heading encoding in the macaque ventral intraparietal area (VIP)", Eur. J. Neurosci. 16(8), 1554 (2002). doi: 10.1046/j.1460-9568.2002.02207.x

29. I.E. Holliday, T.S. Meese and G.R. Barnes, “Evoked magnetic fields to optic flow stimuli are largest for expansion", Perception 27, 17 (1998).doi: 10.1068/v980377

30. M. Edwards and D.R. Badcock, "Asymmetries in the sensitivity to motion in depth: a centripetal bias", Perception 22(9), 1013 (1993). doi: 10.1068/p221013

31. K. Tanaka and H. Saito, "Analysis of motion of the visual field by direction, expansion/contraction, and rotation cells clustered in the dorsal part of the medial superior temporal area of the macaque monkey", J. Neurophysiol. 62(3), 626 (1989). 